\title{
Medical students' perceptions of their learning environment during clinical years at Chitwan Medical College in Nepal
}

This article was published in the following Dove Press journal:

Advances in Medical Education and Practice

\author{
Dev Kumar Shah' \\ Suneel Piryani ${ }^{2}$ \\ Rano Mal Piryani ${ }^{3}$ \\ Mohammad Nazrul Islam' \\ Rajesh Kumar Jha ${ }^{4}$ \\ Gopendra Prasad Deo ${ }^{5}$ \\ 'Department of Physiology, ${ }^{2}$ Department \\ of Community Medicine \& Public Health, \\ ${ }^{3}$ Internal \& Pulmonary Medicine and \\ Medical Education, ${ }^{4}$ Department of \\ Pharmacology, ${ }^{5}$ Department of \\ Anesthesiology, Chitwan Medical \\ College, Bharatpur, Chitwan, Nepal
}

Correspondence: Rano Mal Piryani Health Professions Training Committee, Universal College of Medical Sciences,

Bhairahawa, Nepal

Tel +977984 I269522

Email r_piryani@hotmail.com
Background: The educational environment of an institution affects learning and has a significant role in determining students' academic achievement. The objective of the study was to determine the undergraduate medical students' perception about educational environment in clinical years of study utilizing Dundee Ready Education Environment Measure (DREEM) questionnaire.

Methods: A descriptive cross-sectional questionnaire-based study was conducted among fourth and fifth-year medical students toward the end of their 2016 academic year in Chitwan Medical College, Bharatpur, Nepal. The 50-item DREEM questionnaire was used to collect the data. The items were scored based on a 5-point Likert scale. The data were analyzed using SPSS version 20. Scores obtained were expressed as mean \pm SD.

Results: The mean total DREEM score was 122/200. The mean score for Students' Perceptions of Learning, Students' Perceptions of Teachers, Students' Academic SelfPerceptions, Students' Perceptions of Atmosphere, and Students' Social Self-Perceptions were $29.8 / 48,25.9 / 44,20.3 / 32,28.6 / 48$, and 17.27/28, respectively. This shows the environment for learning was satisfactory. There were nine problem areas with a mean score of $\leq 2$. There was no significant difference observed in educational environment subscales scores according to enrollment year, gender, or funding source for education.

Conclusion: The overall student's perception of the educational environment was satisfactory. Nevertheless, the study revealed some problematic areas in the learning environment which require remedial measures to make the environment more conducive for learning to satisfy the students and achieve a far better outcome.

Keywords: DREEM, educational environment, medical students, Nepal, perception

\section{Introduction}

In Nepal, stakeholders have been interested and concerned regarding the quality of medical education delivered by the private medical colleges in recent years. Further, the quality of education in private medical colleges of Nepal has gained the substantial attention of national news media and citizens. The academic quality of any medical school/institution is reflected in its educational environment for learning. ${ }^{1}$

Educational environment for learning is one of the most significant determinants of an effective implementation of curriculum. ${ }^{2}$ Students' perception of the educational environment is crucial for improving and modifying the quality of medical education. Students' perceptions about the educational environment significantly 
influenced the learning. ${ }^{3}$ Educational environment has a significant impact on students' achievement, satisfaction, and success. ${ }^{4}$ The role of a teacher/facilitator, atmosphere, number of (formal) learning opportunities, and available facilities in the institute are among the important determinants of the educational environment. ${ }^{1,5}$

According to Harden, measurement of educational environment for learning act as a foundation for the analysis of prevailing practices within the institution. The measurement may be the basis for making required adjustments for state of art education practices in alignment with goals of the institution. ${ }^{6,7}$ Dundee Ready Education Environment Measure (DREEM) developed by McAleer and Roff was used to assess the educational environment. ${ }^{6}$ The DREEM has continuously been used globally in medical schools and other health professions institutes to produce diagnostic analyses of undergraduate educational environments. ${ }^{8}$ This is a culturally nonspecific, generic validated tool which has been found to be highly reliable in variety of settings including health care-related programs., 90

In clinical settings, maintaining friendly, motivating, and non-humiliating educational environment for learning for the students is more challenging for the person who performs a dual role as a teacher and clinician. There is limited research assessing medical students' perception about educational environment for learning in clinical years of undergraduate study at private medical colleges in Nepal. Chitwan Medical College (CMC) is among the best medical colleges in the private sector in Nepal located in Bharatpur. Hence, this study was conducted in CMC with the objective to determine the undergraduate medical students' perception about educational environment in clinical years of study utilizing DREEM questionnaire. With this, both strengths and weakness would be known to bring change.

\section{Methods}

\section{Study design and participants}

A descriptive cross-sectional questionnaire-based study was conducted among fourth and fifth-year Bachelor of Medicine, Bachelor of Surgery (MBBS) students of CMC, Bharatpur Nepal toward the end of their academic year 2016. Of 200 medical (MBBS) students, 125 (75 from the fourth year and 50 from the fifth year) consented to participate in the study voluntarily. Only 103 students duly filled the questionnaire with a response rate of $82.4 \%$. The 22 incomplete questionnaires were excluded from the study, and 103 students' responses were considered for the analysis.

\section{Study area}

CMC is a private medical institute, affiliated to Tribhuvan University Kathmandu Nepal offering a five and half years undergraduate MBBS program (two years basic science courses, two and half years clinical sciences courses, and one year mandatory internship). CMC established in 2006 is located in tarai (plain) region of Nepal at Bharatpur city in the southwestern part of province three. CMC has been running both undergraduate and postgraduate programs in medicine, dentistry, basic sciences, nursing, and allied sciences. CMC has 750 bedded teaching hospital located at the center of east-west highway in Bharatpur city.

\section{Assessment instrument and scoring}

DREEM questionnaire was used for this study. DREEM is a 50-item scale (closed-ended questionnaire) with five subscales: Students' Perceptions of Learning (SPL) (12 items), Students' Perceptions of Teachers (SPT) (11 items), Students' Academic SelfPerceptions (SASP) (8 items), Students' Perceptions of Atmosphere (SPA) (12 items), and Students' Social Self-Perceptions (SSSP) (7 items). Each item has response options along a 5-point Likert scale ranging from 0 (strongly agree) to 4 (strongly disagree). Among these 50 DREEM items, 9 are negative items for which questionnaires were reversely scored. The total score of scales was 200 points (50 items with maximum 4 points each). ${ }^{6,8}$

\section{Data collection and analysis}

A self-administered and structured questionnaire was used to collect data. The purpose of the study and process of data collection were explained before the administration of the questionnaire. The importance of responding to all 50 items of the questionnaire was elucidated to the participants. The data were entered into an electronic database using software Epidata 3.1. Data were analyzed as per the objective of the study through the SPSS version 20. The descriptive statistical analysis of data was performed to determine the mean and standard deviation. The Chisquare test was used to test the significant difference of scores in terms of gender, year, and source of funding for the education. $P$-value $<0.05$ was considered as significant.

\section{Ethical approval}

The study proposal was approved by the Institutional Review Committee (IRC) of CMC, Nepal letter no 
CMC_IRC-135 January 3, 2016. Informed verbal consent was taken from the students before participating in the study. Students' verbal consent process was approved by IRC of CMC. The confidentiality of the data provided by the participants was maintained.

\section{Results}

Of 200 medical (MBBS) students, 125 (75 from the fourth year and 50 from the fifth year) consented to participate in the study voluntarily. Only 103 students duly filled the questionnaire with a response rate of $82.4 \%$.

Of 103 participants, 66 were male and 37 female students. Sixty students were from MBBS fourth year and 43 from fifth year. Among them, 99 students had self-funded for their education while 4 students were scholarship awardee. The average age of participants was $22.8 \pm 1.1$ years. (Table 1 )

The total score of scales was 200 points (50 items with maximum 4 points each). A score of $0-50$ indicates "very poor", 51-100 indicates "plenty of problems", while a score of 101-150 is "more positive than negative" and a score of 151-200 is "excellent" educational environment. An environment with a score of 100 is viewed with considerable ambivalence by the students and as such needs to be improved. The result obtained for subscales was also interpreted as per the guidelines of McAleer and Roff. ${ }^{6}$

The responses to individual items were considered to identify more specific strengths and weaknesses within the educational climate of CMC. Items with a mean score of 3.5 or over were taken as real positive points. Items with a mean between 2 and 3 were considered as aspects of the climate that could be enhanced while items with a mean of 2 or less were taken as problem areas in the learning environment according to the guidelines. $^{6}$

Table I Characteristics of participating students

\begin{tabular}{|c|c|c|}
\hline \multicolumn{2}{|c|}{ Characteristics } & \multirow[b]{2}{*}{$\begin{array}{l}N=66(64 \%) \\
N=37(36 \%)\end{array}$} \\
\hline Sex & $\begin{array}{l}\text { Male } \\
\text { Female }\end{array}$ & \\
\hline Age, years & & $22.8 \pm 1.1$ \\
\hline Year of study & $\begin{array}{l}\text { Fourth-year MBBS } \\
\text { Fifth-year MBBS }\end{array}$ & $\begin{array}{l}N=60(58 \%) \\
N=43(42 \%)\end{array}$ \\
\hline Category & $\begin{array}{l}\text { Self-funded } \\
\text { Scholarship awardee }\end{array}$ & $\begin{array}{l}N=99(96 \%) \\
N=04(04 \%)\end{array}$ \\
\hline
\end{tabular}

Abbreviations: MBBS, bachelor of medicine and bachelor of surgery; N, number.
Table 2 presents the DREEM domains and overall scores. The mean of overall DREEM score was 122/200 which indicates students' perceptions were more positive than negative (overall score $=101-150$ ) according to the practical guide of McAleer and Roff. ${ }^{6}$ The mean domain scores for SPL was 29.8/48, SPT 25.9/44, SASP 20.3/32, SPA 28.6/48, and SSSP 17.27/28.

Table 3 depicts the participants' response to individual items of DREEM. Most of the items had a mean score between 2 and 3. No items had real positive points, ie, a mean score of 3.5 or over. Mean score of item no. 3, 9, 11, $12,14,27,39,48$ and 50 was $<2$ which indicates the problem areas and need to be focused strictly. There was no significant difference in the perception of students according to gender, year of enrollment, and funding source for education.

\section{Discussion}

This study aimed to assess students' perception regarding the educational environment for learning during clinical years of undergraduate study in one of the private medical colleges of Nepal using validated DREEM questionnaire. DREEM is a valuable tool for assessing educational environments for learning as it is highly reliable in health care profession and culturally non-specific. ${ }^{9,10}$

It is evident from the response rate (82.4\%) that there was reasonable participation from the students in the current study. The lowest response rate was in one study conducted in Saudi Arabia (2004) and highest response rate was in another study also conducted in Saudi Arabia (2013). This reveals that in the current study the response rate was above average. ${ }^{11,12}$

The overall mean DREEM score in this study was found to be 122/200 which is higher than the medical schools in India (2008), Iran (2010), Saudi Arabia (2013), and Kuwait (2015) but lower than studies conducted in government-run medical institute in Nepal (2001), Pakistan (2011), India (2017), and Saudi Arabia (2017). ${ }^{13-20}$

This study did not find any significant difference in the perception of students according to gender, year of enrollment, and funding source for education (scholarship vs self-funded). This finding is comparable with studies conducted in India (2008) and Saudi Arabia (2013); however, studies done earlier reported lower mean DREEM scores for female students compared to the males. ${ }^{14,15,21}$

The score of all the five domains of DREEM in this study revealed satisfactory perception level. The mean 
Table 2 Mean (SD) DREEM domain scores of MBBS clinical years students

\begin{tabular}{|l|l|l|l|}
\hline & Number of questions & Maximum DREEM score & Mean \pm SD score \\
\hline Students' Perception of Learning (SPL) & 12 & 48 & $29.80 \pm 6.0$ \\
Students' Perception of Teachers (SPT) & $1 \mathrm{I}$ & 44 & $25.90 \pm 4.6$ \\
Students' Academic Self-Perception (SASP) & 8 & 32 & $20.30 \pm 3.4$ \\
Students' Perceptions of Atmosphere (SPA) & 12 & 48 & $28.60 \pm 5.0$ \\
Students' Social Self Perceptions (SSSP) & 7 & 28 & $17.27 \pm 2.5$ \\
Total DREEM score & 50 & 200 & $122.0 \pm 18.0$ \\
\hline
\end{tabular}

Abbreviations: DREEM, dundee ready education environment measure; SD, standard deviation; MBBS, bachelor of medicine, bachelor of surgery.

score for the perception of learning was 29.8/48 which indicates a more positive perception. The same level of perception was recorded among third-year medical students studying in government medical institute in Nepal (2001) and India (2008). ${ }^{13,14}$

When the scores of individual items of perception of learning domain were looked into, it was found all those items indicated that the climate in the medical school could be enhanced (mean score range: $2-3$ ) except one problematic area (mean score $\leq 2$ ), ie, teaching is too teachercentered. This might be due to teaching conducted in the large group both in lecture and clinical postings where the teacher cannot focus attention to individual students. Though the response to item 13 (the teaching is studentcentered) indicates that student-centered approach could be enhanced, even the lesser score (mean: 1.85) for item no. 48 (teaching is too teacher-centered) should be considered earnestly, and necessary measures should be endorsed to enhance teachers' competencies and capacities for studentcentered interactive teaching-learning activities.

This study revealed that teachers were moving in the right direction as per the students' perception of their teachers (SPT score: 25.9/44). This finding is comparable with findings of studies conducted in Nepal (2001) 26.21 and Saudi Arabia (2013) 25.3 among clinical phase students. ${ }^{13,15}$ On the contrary, the results of this study also reported the problematic areas that the teachers are authoritarian and they get angry in the class. Therefore, the teachers must be encouraged to trail and follow the adult learning principles and create a friendlier learning environment.

Students participated in this study were feeling more inclined toward the positive side of their academic activities (SASP score 20.3/32) which is a good sign. This finding is consistent with the findings of studies carried out among clinical students in Nepal (2001) 21.96, Saudi Arabia (2013) 20.1 and India (2008) 20. ${ }^{13-15}$ Students recorded a higher score on being confident about passing the academic year but also admitted difficulty in memorizing all that was needed. Attending the lectures as well as clinical postings might have affected the time management for the self-study, and the revision/recall of the subject matters or might be an erroneous perception.

Overall, there was more positive attitude toward the present atmosphere of the college (SPA score 28.6/48) revealed from this study. This is slightly less but not significantly different from finding of earlier study conducted in Nepal (2001) 32.2/48. ${ }^{13}$ However, the students did not perceive the relaxed atmosphere during ward teaching, and the timetable in the college was not satisfactory. The participants of the study conducted in Saudi Arabia (2013) perceived the same problem in their school but the participant of a study carried out in Nepal (2001) perceived ward teaching comparably better. ${ }^{13,15}$ Participants of this study disclosed that they irritated the teachers despite their general perception moving in the right direction for their teachers. Such behavior might have forced teachers to become authoritarian and lose temper sometimes in the classroom and might be vice versa. The workload and busy schedule of the clinician, as well as large group size during ward teaching, might have stressed the environment. The non-adherence to the scheduled timetable for the lectures, internal assessment, seminars, and discussion were the major verbal complains of the students.

SSSP was found not too bad (score 17.2/28) which is comparable to findings of a study conducted earlier in Nepal (2001) 18.3. ${ }^{13}$ Majority of the students reported that they have good friends in this medical school but they were not satisfied; the dis-satisfaction could be with the available support system for the stressed-out students or they were bored on this course. The studies done in Australia and Europe attributed stress to exam anxiety whereas finance was identified as a major contributing 


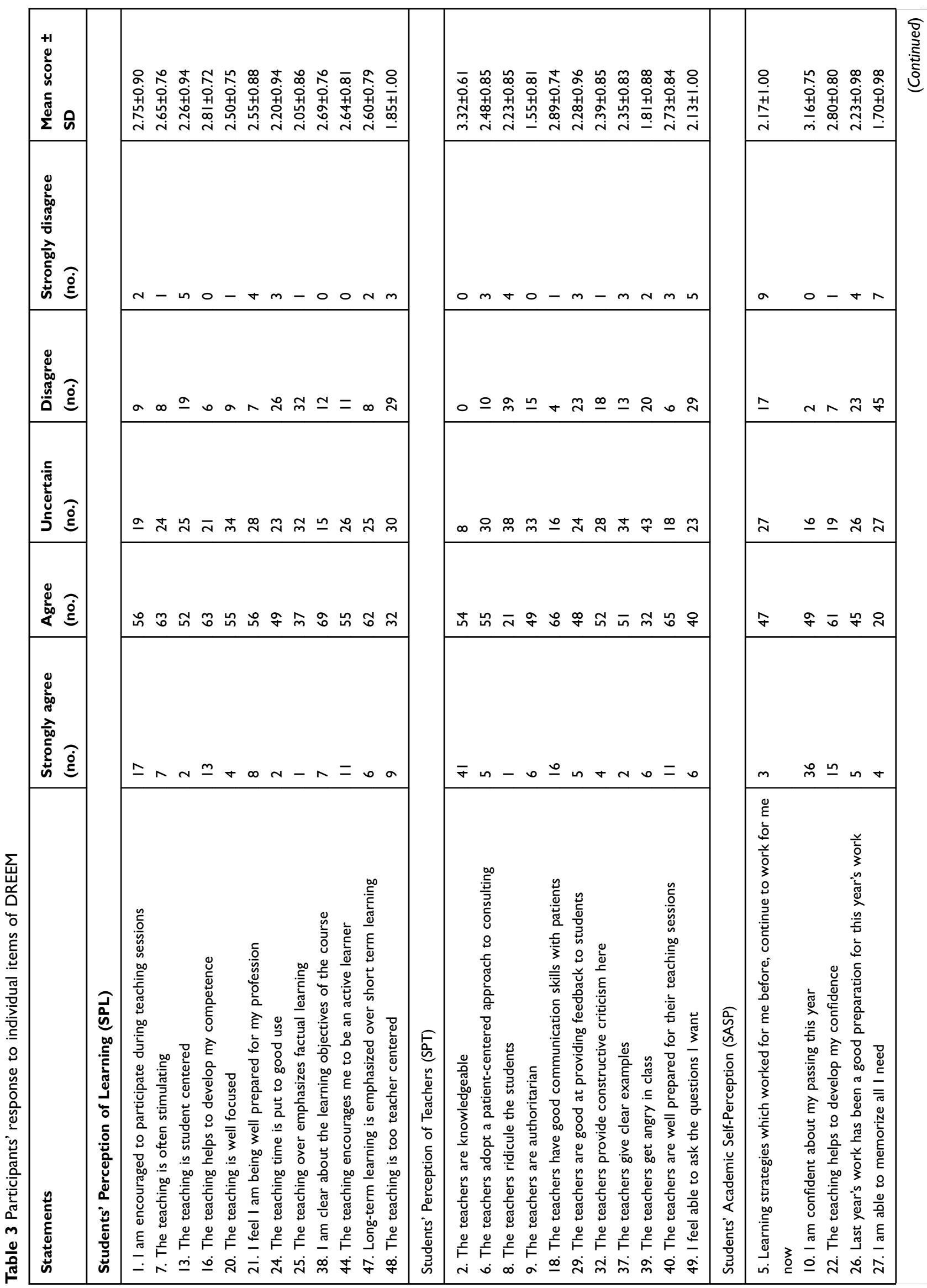




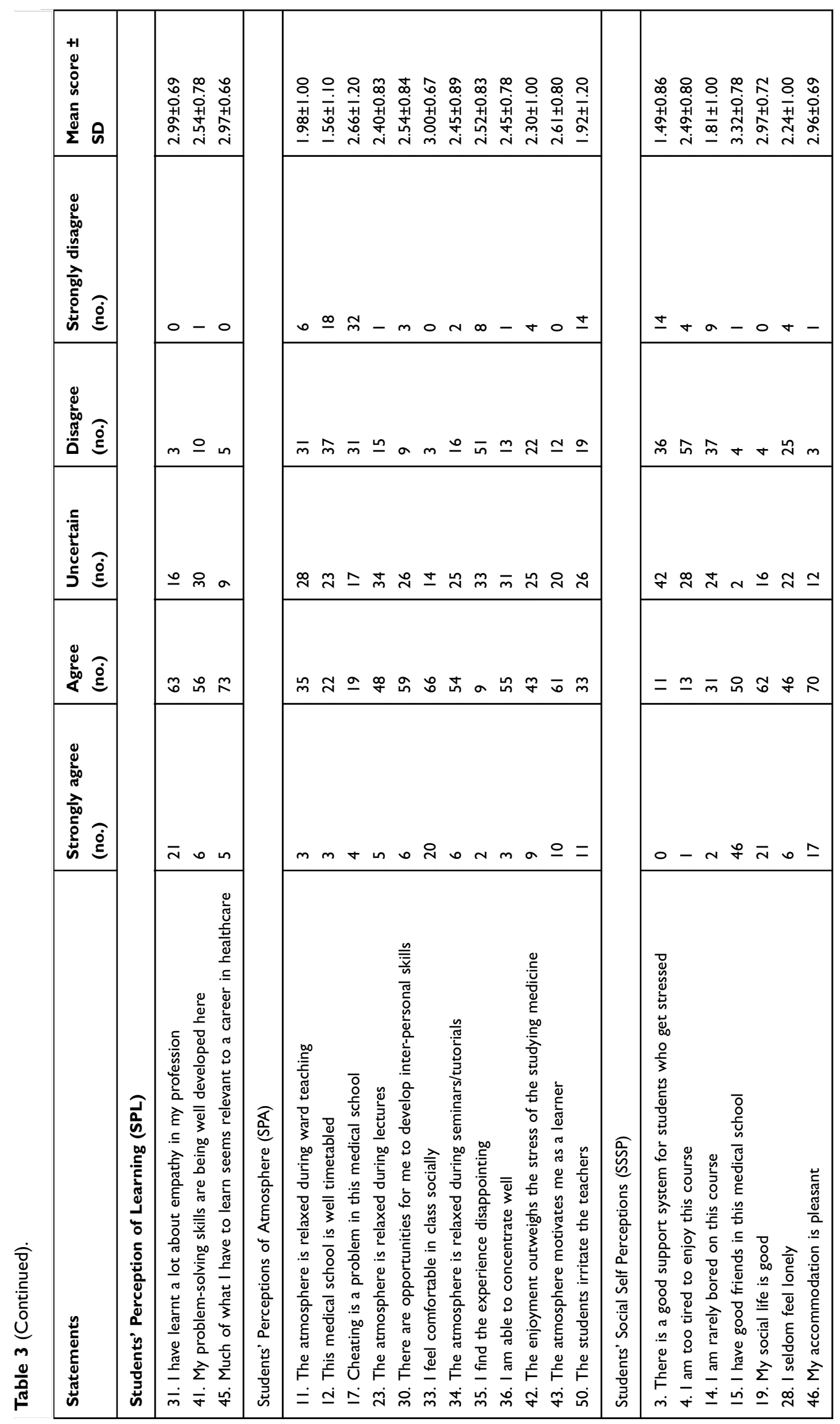


factor in Canada. ${ }^{7}$ Also, it is advisable to develop student support and counseling unit in the teaching hospital which could provide academic support, career guidance, and address the health problem and financial matters of the student. Furthermore, the students getting bored in their medical course is a serious issue as it can incredibly affect their professionalism in the future. The reasons for such perception must be explored individually and counseled solemnly.

This study findings regarding the learning environment in the clinical settings of a relatively newly established private medical college indicates that the prime factors of the learning environment in a medical school are beyond the logistics and physical facilities available in the institutes. Participants recorded none of the items in the questionnaire as real positive points; however, most of the items were scored for enriching the environment. This study also discovered some problematic areas in the medical school environment. Collaboration and motivation of stakeholders and incorporation of interactive teachinglearning methods and small group teaching may resolve the problematic areas of the medical school.

\section{Conclusion}

This study highlights the learning environment in clinical years in one of the private medical colleges of Nepal. The overall DREEM score suggested more positive than the negative perception of students regarding the environment in their school. The students' perception of learning, their teachers, atmosphere, and their academics and social selfperception were found to be satisfactory, not excellent. Therefore, necessary measures need to be adopted in all domains of the learning environment to take it toward excellence. Some problematic areas in students' perspective were also delineated and need to be addressed by the faculty and management team of the college. The similar studies need to be conducted in other medical colleges of Nepal. These will highlight the strengths and weaknesses regarding educational environment in individual institution and help to adopt better teaching-learning practices and ultimately improve the academic environment of medical schools.

\section{Abbreviation list}

DREEM, Dundee Ready Education Environment Measure; MBBS, Bachelor of Medicine, Bachelor of Surgery; SPL, Students' Perceptions of Learning; SPT, Students' Perceptions of Teachers; SASP, Students'Academic Self-
Perceptions; SPA, Students' Perceptions of Atmosphere; SSSP, Students' Social Self-Perceptions.

\section{Acknowledgments}

We acknowledge Mr Govinda Prasad Dhungana, Assistant Professor, Department of Community Medicine, Chitwan Medical College, Nepal, for helping in the statistical analysis of data. This work is not funded by any organization.

\section{Disclosure}

The authors report no conflicts of interest in this work.

\section{References}

1. Hutchinson L. ABC of learning and teaching: educational environment. BMJ. 2003;326(7393):810. doi:10.1136/bmj.326.7402.1329-b

2. Ostapczuk M, Hugger A, de Bruin J, Ritz-Timme S, Rotthoff T. DREEM on, dentists! Students' perceptions of the educa- tional environment in German dental school as measured by the Dundee Ready Education Environment Measure. Eur $J$ Dent Educ. 2012;16:67-77. doi:10.1111/j.1600-0579.2011.00720.x

3. Pimparyon P, Roff S, McAleer S, Poonchai B, Pemba S. Educational environment, student approaches to learning and academic achievement in a Thai nursing school. Med Teach. 2000;22(4):359-364. doi:10.1080/014215900409456

4. Genn JM. AMEE Medical Education Guide No. 23 (Part 1): curriculum, environment, climate, quality and change in medical education-a unifying perspective. Med Teach. 2001;23(4):337-344. doi:10.1080/ 01421590120063330

5. Schönrock-Adema J, Bouwkamp-Timmer T, van Hell EA, CohenSchotanus J. Key elements in assessing the educational environment: where is the theory? Adv Health Sci Educ. 2012;17(5):727-742. doi:10.1007/s10459-011-9346-8

6. Roff S, McAleer S, Harden RM, et al. Development and validation of the Dundee ready education environment measure (DREEM). Med Teach. 1997;19(4):295-299. doi:10.3109/ 01421599709034208

7. Umber A, Khan S, Hussnaian M, Ihsan S. Educational Environment at University Medical and Dental College, FSD. Annals. 2011;17 (3):292-298.

8. Menaka DS, Lokuhetty MDS, Warnakulasuriya SP, Perera RIR, De Silva HTR, Wijesinghe HD. Students' perception of the educational environment in a Medical Faculty with an innovative curriculum in Sri Lanka. South-East Asian J Med Educ. 2010;4(1):9-16.

9. Kohli V, Dhaliwal U. Medical students' perception of the educational environment in a medical college in India: a cross-sectional study using the Dundee Ready Education Environment questionnaire. $J$ Educ Eval Health Prof. 2013;10:5. doi:10.3352/jeehp.2013.10.5

10. Tontuş H. DREEM; dreams of the educational environment as its effect on education result of 11 Medical Faculties of Turkey. J Exp Clin Med. 2010;27:104-108. doi:10.5835/jecm.omu.27.03.002

11. Al-Hazimi A, Zaini R, Al-Hyiani A, et al. Educational environment in traditional and innovative medical schools: a study in four undergraduate medical schools. Educ Health (Abingdon). 2004;17:192203. doi:10.1080/13576280410001711003

12. Shorman HA, Ahmad MS. Assessment of the educational environment in a newly established dental college. J Educ Ethics Dent. 2013;3:6-13. doi:10.4103/0974-7761.126935

13. Roff S, McAleer S, Ifere OS, Bhattacharya S. A global diagnostic tool for measuring educational environment: comparing Nigeria and Nepal. Med Teach. 2001;23(4):378-382. doi:10.1080/01421590120043080 
14. Abraham R, Ramnarayan K, Vinod P, Torke S. Students' perceptions of learning environment in an Indian medical school. BMC Med Educ. 2008;8(1):20. doi:10.1186/1472-6920-8-20

15. Al-Mohaimeed A. Perceptions of the educational environment of a new medical school, Saudi Arabia. Int J Health Sci. 2013;7(2):150. doi:10.12816/0006039

16. Aghamolaei T, Fazel I. Medical students' perceptions of the educational environment at an Iranian Medical Sciences University. BMC Med Educ. 2010;10(1):87. doi:10.1186/1472-6920-10-87

17. Karim J, Becher Al-Halabi YM, Sadeq H, Dawas A, AlAbdulrazzaq D. The educational environment of the undergraduate medical curriculum at Kuwait University. Adv Med Educ Pract. 2015;6:297.

18. Khan JS, Tabasum S, Yousafzai UK, Fatima M. DREEM on: validation of the dundee ready education environment measure in Pakistan. JPMA-J Pak Med Assoc. 2011;61(9):885.
19. James D, Mani S, Mathew A, Velusamy SK. Perceptions of the educational environment at entry and exit of medical students to clinical teaching in a rural medical college. Int J Res Med Sci. 2017;5(6):2601-2607. doi:10.18203/2320-6012.ijrms20172455

20. Soliman MM, Sattar K, Alnassar S, et al. Medical students' perception of the learning environment at King Saud University Medical college, saudi Arabia, using DrEEM inventory. Adv Med Educ Pract. 2017;8:221. doi:10.2147/AMEP.S127318

21. Till H. Identifying the perceived weaknesses of a new curriculum by means of the Dundee Ready Education Environment Measure (DREEM) inventory. Med Teach. 2004;26(1):39-45. doi:10.1080/ 01421590310001653937

\section{Publish your work in this journal}

Advances in Medical Education and Practice is an international, peerreviewed, open access journal that aims to present and publish research on Medical Education covering medical, dental, nursing and allied health care professional education. The journal covers undergraduate education, postgraduate training and continuing medical education including emerging trends and innovative models linking education, research, and health care services. The manuscript management system is completely online and includes a very quick and fair peer-review system. Visit http://www.dovepress.com/testimonials.php to read real quotes from published authors. 